"This is the pre-peer reviewed version of the following article: Luís A, Marcelino $H$, Rosa C, Domingues F, Pereira L, Cascalheira JF. 2020 Adenosine inhibits human astrocyte proliferation independently of adenosine receptor activation. European J. Pharmacology 876,173055 , which has been published in final form at https://doi.org/10.1016/j.ejphar.2020.173055. This article may be used for noncommercial purposes in accordance with Elsevier Terms and Conditions for Use of Self-Archived Versions."

The effects of cannabinoids on glioblastoma growth: a systematic review with meta-analysis of animal model studies

Ângelo Luís ${ }^{1,2}$, Helena Marcelino ${ }^{1,3}$, Carolina Rosa ${ }^{1}$, Fernanda Domingues ${ }^{1,3}$, Luísa Pereira $^{2,4}$, José Francisco Cascalheira ${ }^{1,3, *}$

${ }^{1}$ Centro de Investigação em Ciências da Saúde (CICS-UBI), Universidade da Beira Interior, Av. Infante D. Henrique, 6200-506 Covilhã, Portugal

${ }^{2}$ Grupo de Revisões Sistemáticas da Literatura (GRUBI), Faculdade de Ciências da Saúde, Universidade da Beira Interior, Av. Infante D. Henrique, 6200-506 Covilhã, Portugal

${ }^{3}$ Departamento de Química, Faculdade de Ciências, Universidade da Beira Interior, Rua Marquês d'Ávila e Bolama, 6201-001 Covilhã, Portugal

${ }^{4}$ Centro de Matemática e Aplicações (CMA-UBI), Universidade da Beira Interior, Rua Marquês d'Ávila e Bolama, 6201-001 Covilhã, Portugal

*Corresponding author: Prof. José Francisco Cascalheira; email: jfcascalheira@ubi.pt; Tel.: +351275329 259; Fax: +351275319730.

\title{
ORCID of authors:
}

Ângelo Luís: 0000-0003-0712-6522

Helena Marcelino: 0000-0002-6218-6192

Carolina Rosa: 0000-0002-4684-5661 
Fernanda Domingues: 0000-0002-9540-0853

Luísa Pereira: 0000-0002-9068-4607

José Francisco Cascalheira: 0000-0002-5315-3866

\begin{abstract}
Introduction: Glioblastoma multiforme (GBM) is the most frequent and aggressive malignant brain tumour, with a poor prognosis despite available surgical and radiochemotherapy, rising the necessity for searching alternative therapies. Several preclinical studies evaluating the efficacy of cannabinoids in animal models of GBM have been described, but the diversity of experimental conditions and of outcomes hindered definitive conclusions about cannabinoids efficacy.

Methods: A search in different databases (Pubmed, Web of Science, Scopus and SciELO) was conducted during June 2019 to systematically identify publications evaluating the effects of cannabinoids in murine xenografts models of GBM. The tumour volume and number of animals were extracted, and a random effects meta-analysis of these results was performed to estimate the efficacy of cannabinoids. The impact of different experimental factors and publication bias on the efficacy of cannabinoids was also assessed.
\end{abstract}

Results: Nine publications, which satisfied the inclusion criteria, were identified and subdivided in 22 studies involving 301 animals. Overall, cannabinoid therapy reduced the fold of increase in tumour volume in animal models of GBM, when compared with untreated controls. The overall weighted standardized difference in means (WSDM) for the effect of cannabinoids was -1.399 (95\% CI: -1.900 to -0.898 ; $p$-value $<0.0001)$. Furthermore, treatment efficacy was observed for different types of cannabinoids, alone or in combination, and for different treatment durations. Cannabinoid therapy was still effective after correcting for publication bias.

Conclusions: The results indicate that cannabinoids reduce the tumour growth in animal models of GBM, even after accounting for publication bias. 
Keywords: cannabinoids, glioblastoma multiforme, animal model studies, systematic review, meta-analysis

\section{Introduction}

The incidence in adults of newly diagnosed glioblastomas is $0.59-3.69$ cases per 100,000person life-years (Dumitru et al., 2018). Glioblastoma multiforme (GBM), also known as grade IV astrocytoma, is simultaneously the most common class of malignant brain tumours and one of the most aggressive types of cancer. Therefore, after the diagnostic, patients usually live just more 6-12 months, which is related mostly with the high invasiveness and proliferation rate of GBM (Velasco et al., 2007). The existing guidelines for therapeutic approaches to treat GBM (surgical resection and focal radiotherapy) are simply palliative (Guzmán et al., 2006). Several chemotherapeutic compounds, such as alkylating agents (e.g. temozolomide - TMZ) and nitrosoureas (e.g. carmustine) have also been assessed, but increase in survival of patients was only moderate (Guzmán et al., 2006). Only TMZ showed some clinical efficacy in a phase III clinical trial (Stupp et al., 2005). Furthermore, GBM presents a high-level of resistance to the standard chemotherapy and radiotherapy (Torres et al., 2011). For that reason, the search for new promising compounds to treat GBM is essential.

Cannabinoids, the bioactive compounds of Cannabis sativa L., exert their effects using certain types of G-proteins coupled receptors, which are usually triggered by a group of endogenous ligands, the endocannabinoids (Blázquez et al., 2008). The endocannabinoid system was found when studying the main bioactive compound of $C$. sativa, $\Delta^{9}$ tetrahydrocannabinol (THC) (Allister et al., 2005).

Several preclinical experiments indicate that drugs mimicking the endocannabinoid system may be applied to prevent cancer growth (Rocha et al., 2014). In fact, it was demonstrated that cannabinoids may be able to regulate both the cell growth and death in various types of cancer (Allister et al., 2005). In early 2000 were published the first 
studies demonstrating the anti-tumour effects of several cannabinoids in animal models of glioma (Massi et al., 2004; Recht et al., 2001; Sánchez et al., 2001a). These studies encouraged the first pilot phase I clinical trial including a reduced number of patients (Guzmán et al., 2006), which showed safety of THC administration and indicated its antiproliferative activity. Since then, several preclinical studies using animal models were published, most of them reporting the capacity of cannabinoids in reducing the progression of GBM (Dumitru et al., 2018; Erices et al., 2018; McAllister et al., 2015; Rocha et al., 2014).

The use of animal models is of major importance in research aiming the improvement of human health care (Hooijmans et al., 2014). Although some recent reviews had been published reporting animal studies of anti-tumour effect of cannabinoids on GBM (Dumitru et al., 2018; Erices et al., 2018), a meta-analysis of these studies was not performed yet. There are several benefits in conducting meta-analyses on data from animal studies; they can be used to inform clinical trial design, or to test and explain discrepancies between preclinical and clinical trial results (Vesterinen et al., 2014).

The objective of this work was to perform a systematic review, complying with the PRISMA (Preferred Reported Items for Systematic Reviews and Meta-Analysis) statement, followed by meta-analysis of results obtained using animal models on the effects of cannabinoids in GBM growth, to clarify the therapeutic potential of those compounds.

\section{Methods}

\subsection{Search strategy, inclusion criteria and study selection}

The electronic search for this systematic review was undertaken on various databases (Pubmed, Web of Science, Scopus and SciELO) during June 2019. The databases were queried using the Boolean operator tools, with the following strategy: (cannabinoid* OR cannabi*) AND (glioblastoma OR astrocytoma OR glioma OR oligodendroglioma OR GBM OR glioblastoma multiforme). The references of the articles considered relevant were also verified to find additional works. Following the PRISMA statement (Moher et al., 2015, 2009), titles and abstracts of the selected articles were firstly screened and the full texts of those considered important were then analysed in detail. The literature selection procedure was performed independently by two authors, being a third consulted in case of disagreements. To be included in this systematic review, studies must accomplish the following criteria: to use human-derived cells in animal models 
(xenografts), to present a control group (vehicle), to show the result of the outcome (tumour volume) at the beginning and at the end of the treatment with cannabinoids, and to indicate the standard deviation (SD) of the measurements and the animal number per group.

\subsection{Risk of bias assessment}

The methodological quality of the includes studies was evaluated by a 9-item quality checklist adapted from the CAMARADES (Collaborative Approach to Meta-Analysis and Review of Animal Data in Experimental Studies) published criteria, which comprise: 1) publication in a peer-reviewed journal; 2) reporting the number of tumour cells implanted; 3 ) reporting the randomized allocation of tumour-bearing animals to treatment and control groups; 4) blinded assessment of outcome; 5) sample size calculation; 6) compliance with animal welfare regulations; 7) potential conflicts of interest; 8) number of animals originally inoculated with tumour cells; and 9) explanation of any treated animals excluded from analysis (J. A. Hirst et al., 2014; T. C. Hirst et al., 2014).

\subsection{Data extraction and synthesis}

After the selection of the studies, the included ones were carefully analysed and the following data were extracted and summarized: first author's last name, year of publication, type of GBM cells and intervention, tumour implantation site, outcome analysed, model used, dose of cannabinoid(s) and duration of the treatment. The revision and extraction of the data were independently performed by two authors applying a prespecified protocol, being a third reviewer consulted to analyse discrepancies in data extraction. The results extracted were both initial and post-intervention mean values of tumour volume with the corresponding SD and were then converted in terms of fold of increase. The results of tumour volume were generally reported in Figures in the original studies, and for that reason the Inkscape program (Version 0.92.4) was used to obtain the numerical values to perform the statistical analysis.

\subsection{Statistical analyses}

The present meta-analysis was performed to clarify the effects of cannabinoids on GBM growth by summarizing the results of studies in which the cannabinoids were administered in animals inoculated with human-derived GBM cells. For the outcome of interest, an assessment was performed on the pooled effect of the treatment with 
cannabinoids in terms of weighted standardized difference in means (WSDM) between the change from pre- and post-treatment mean values of the intervention and control groups. Data statistical analysis was undertaken using Comprehensive Meta-Analysis software (Version 2.0) by introducing the number of animals, the fold of increase and respective SD values of the outcome for intervention and control groups, being the random effects model employed (Borenstein et al., 2009). Forest plots were generated to illustrate the study-specific effect sizes along with a 95\% confidence interval (CI). The statistic $\mathrm{I}^{2}$ of Higgins was used as a measure of inconsistency across the findings of the included studies. The scale of $\mathrm{I}^{2}$ has a range of 0 to $100 \%$ and values on the order of $25 \%$, $50 \%$ and $75 \%$ are considered low, moderate and high heterogeneity, respectively (Higgins et al., 2003). Subgroup analysis was performed on the outcome under study, per the model used, type of cannabinoids and duration of the treatment, in order to evaluate the impact of these experimental factors on the cannabinoid effect size and to explore potential sources of heterogeneity. The Chi-square test was employed to assess whether there is homogeneity between the different subgroups with respect to the effect under study.

Three different analyses were used to assess the potential impact of publication bias on the present meta-analysis: 1) Funnel plot (Light et al., 1994; Light and Pillemer, 1984); 2) Egger's regression test (Borenstein et al., 2009; Egger et al., 1997); 3) Duval and Tweedie's Trim and Fill approach (Duval and Tweedie, 2000a, 2000b), which allows the best estimate of the unbiased pooled effect size to be obtained and creates a funnel plot that includes both the observed studies (shown as blue circles) and the necessary imputed studies (shown as red circles) to obtain the absence of bias.

The sensitivity analysis was also achieved by eliminating each study one at a time to evaluate the stability of the results.

\section{Results}

\subsection{Search and selection of studies}

Among the 40 articles initially identified, 9 met all the inclusion criteria for this systematic review. Figure 1 shows the detailed steps of the article selection process. From the 16 full-text articles assessed for eligibility, 7 were excluded. The reasons for exclusion were mostly the inconsistency in presenting the results (tumour perimeter, weight, diameter) (Duntsch et al., 2006; Recht et al., 2001; Silva et al., 2019), different study designs (Aguado et al., 2007; Singer et al., 2015; Soroceanu et al., 2013) and different 
summary statistics (median) (Fisher et al., 2016). Six of the 9 included studies were divided into different experiments. Finally, 22 studies, totalizing 301 animals, were included in this systematic review and meta-analysis.

\subsection{Included studies and characteristics}

The principal characteristics of the included studies are outlined in Table 1. The studies cover a broad spectrum of cannabinoids both natural and synthetic, together with several types of human-derived GBM cells, which were applied in different types of animal models (xenografts). Furthermore, the cannabinoids were administered to the animals alone or in combination with each other at different doses. Such variables were included in this meta-analysis to explore potential sources of heterogeneity.

\subsection{Risk of bias}

The Supplementary Table 1 shows the study quality scores assessed using the CAMARADES checklist. All the included studies are peer-reviewed publications, reported the number of tumour cells implanted and referred the randomization of the animals for both treatment and control groups. However, none of the studies reported the blind of outcome assessment and have calculated the sample size. Overall, the global quality of the included studies is good (quality scores superior to 4 in a total of 9).

\subsection{Effects of cannabinoids on GBM growth}

The meta-analysis results of the effects of cannabinoids on GBM growth are graphically reported on Figure 2, being the overall results presented in Table 2. It is possible to verify that cannabinoids were able to significantly reduce ( $p$-value<0.0001) the mean fold of increase of tumour volume (WSDM: -1.399 ; $95 \%$ CI: -1.900 to -0.898 ), indicating that, in fact, these compounds acted against GBM. It should be noted that, nevertheless, moderate heterogeneity was observed $\left(\mathrm{I}^{2}=72 \%\right)$.

\subsection{Subgroup and sensitivity analyses}

A subgroup analysis was also undertaken (Table 3) to evaluate the influence of the model used, type of cannabinoids and treatment duration. Regarding the model used, only for subcutaneous xenografts was obtained a significant reduction $(p$-value $<0.0001)$ of the mean fold of increase of tumour volume (WSDM: -1.512 ; 95\% CI: -2.060 to -0.965 ). However, for intracranial xenografts only 2 studies were considered, which may explain 
the absence of statistical significance in this subgroup. Nevertheless, the model used did not account for a significant proportion of the observed heterogeneity $\left(\mathrm{Chi}^{2}=1.082 ; p\right.$ value $=0.298$ ). Concerning the type of cannabinoids, all of them were able to significantly reduce the fold of increase of tumour volume, except the cannabinoid KM-233, but in this case the number of studies, two, is too low to draw definitive conclusions. Regarding the heterogeneity between the types of cannabinoid, it was low for cannabidiol (CBD) but high for THC studies. In fact, the type of cannabinoid explained a significant proportion of the observed heterogeneity, according to the Chi-square test $\left(\mathrm{Chi}^{2}=14.219 ; p\right.$ value $=0.007$ ). Concerning the treatment duration, it did not account for a significant proportion of heterogeneity $\left(\mathrm{Chi}^{2}=1.535 ; p\right.$-value $\left.=0.675\right)$, but it is difficult to establish a definitive conclusion because only one study was considered for both treatments with 8 and 35 weeks. For treatments with 12-15 weeks and 22-27 weeks, significant reduction of the fold of increase of the tumour volume was observed.

The sensitivity analysis was also performed by excluding one or more studies from the analysis to see how this affected the results. The results showed that the pooled effects of cannabinoids on GBM growth did not change substantially if a single or a few studies were omitted (Figure 3). Overall, the sensitivity analysis demonstrated that the findings of this meta-analysis are robust.

\subsection{Publication bias}

To analyse the publication bias, a funnel plot was generated for the outcome considering the Trim and Fill adjustment (Figure 4). It was observed that there are more studies on the right than on the left, and for that reason 2 studies were inputted on the left to adjust the funnel plot to the absence of publication bias. The WSDM both observed and adjusted were reported on Tables 2 and 3.

The presence of publication bias was explored using Egger's regression test. This test indicates evidence of publication bias for the impact of cannabinoids administration on GBM growth. (Table 4).

\section{Discussion}

In this systematic review with meta-analysis of 9 publications, subdivided in 22 studies and involving 301 animals, we found that overall cannabinoid therapy reduced tumour volume in murine xenografts models of GBM. Furthermore, treatment efficacy was 
observed for different types of cannabinoids, alone or in combination, and different treatment durations.

Several previous in vitro and in vivo pre-clinical studies in animal models and pilot studies in human patients (Allister et al., 2005; Guzmán et al., 2006; Ladin et al., 2016) had reported the therapeutic potential of cannabinoids on GBM, based on reduction of tumour growth. However, to the best of our knowledge, the present work is the first systematic review with meta-analysis performed regarding the effects of cannabinoids on GBM.

In the present meta-analysis, the outcome analysed was the fold of increase from initial tumour volume before treatment, rather than median survival time, since most of the studies reported the initial and final volume, or the fold of increase in tumour volume, together with the respective SD or standard error of mean (SEM).

Regarding the site of tumour inoculation, most of the studies included in the present metaanalysis used heterotopic subcutaneous xenografts, with only 2 studies using orthotopic intracranial xenografts. Only for the subcutaneous xenograft model, a significant reduction of tumour volume by cannabinoids was found. Nevertheless, there was no significant variation in cannabinoids effect between tumour models.

The subgroup analysis for different cannabinoids, revealed that most cannabinoids, either natural or synthetic and either alone or in combination, were able to reduce tumour volume of murine GBM models, except for the synthetic cannabinoid KM-233. However, the effect of the different cannabinoids varied, and the type of cannabinoid showed to be a significant source of heterogeneity. Concerning the duration of treatment with cannabinoids, a significant decrease of tumour volume was obtained for the 12-15 weeks and for the 22-27 weeks treatment periods. There was no significant variation between different treatment duration.

In the present analysis, only the studies reporting animals inoculated with tumour cells of human origin were considered. This choice aimed to reduce the heterogeneity among the studies. On the other hand, using cells of human origin constitute a more reliable model/construct of GBM and previous studies suggest that human-derived tumours are more sensitive to chemotherapy than those originated in rodents (Amarasingh et al., 2009).

The overall global quality of the studies included in the present meta-analysis was good. The publication bias of the present meta-analysis was also assessed, and the results indicate its presence, which is usually due to the fact of neutral studies often remain unpublished or take longer to get published than those reporting statistically significant 
results, as previously mentioned (Sena et al., 2014). However, probably this was not the case for the studies considered in the present meta-analysis, since, after correcting for publication bias, the adjusted WSDM was more negative, suggesting a stronger reduction on tumour volume induced by cannabinoids, than the non-adjusted value. However, we cannot exclude that other confounding effects of certain aspects of studies design (including randomization, allocation concealment and blinded outcome assessment) might also constitute source of bias, as commonly happens with animal studies (Amarasingh et al., 2009).

In the present meta-analysis, the results in general presented moderate or high heterogeneity, even after subgrouping for site of cell tumour inoculation, type of cannabinoid or treatment duration. This is common in meta-analysis dealing with data obtained from animal models (Hooijmans et al., 2014), where the cause of heterogeneity is difficult to identify due to experimental differences between studies. Nevertheless, animal studies are crucial to the understanding of disease mechanisms and for testing interventions for safety and efficacy.

The promising results obtained in animal models of GBM, led to 3 pilot clinical trials to assess the efficacy of cannabinoids in GBM patients (Dall'Stella et al., 2019; Guzmán et al., 2006; Kenyon et al., 2018). The first study, conducted-performed in 2006 and enrolling-including 9 patients, showed safety ofthat THC-was safe; however, no clear activity of THC on tumour progression was reported (Guzmán et al., 2006). The study of Kenyon, et al 2018 (Kenyon et al., 2018), enrolled 7 patients treated with CBD and reported extended survival in 4 and slowed disease progression in 3 of the patients. The study of Dall'Stella, et al 2019 (Dall'Stella et al., 2019) enrolled only 2 patients submitted to chemoradiation followed by a multiple drug regimen (procarbazine, lomustine, and vincristine) plus CBD, both patients showed no signs of disease progression for at least 2 years.

The chemotherapeutic options to treat GBM are, in fact, limited. Only TMZ showed clinical efficacy, although modest, in a phase III clinical trial (Stupp et al., 2005), the median survival increasing from 12.1 months with radiotherapy alone to 14.6 months with radiotherapy plus TMZ. Therefore, the potential use of cannabinoids, alone or in combination with other drugs or radiotherapy, to treat GBM deserves further investigation.

Preclinical studies using animal models of GBM, showed that cannabinoids in combination with TMZ produced a stronger anti-tumoural effect than the effect of each 
drug alone (Blázquez et al., 2008; López-Valero et al., 2018a, 2018b). In fact, a phase II clinical trial of 21 patients had been recently conducted. This trial showed that patients treated with a combination of THC and CBD in addition to TMZ had a median survival of >662 days compared with 369 days in the group treated with TMZ alone (Schultz and Beyer, 2017).

In vitro studies showed that cannabinoids may reduce tumour growth by: 1) inducing apoptosis and cytotoxic autophagy); 2) inhibiting cell proliferation, and 3) inhibitingangiogenesis (Dumitru et al., 2018). Cannabinoid-induced activation of the intrinsic apoptotic pathway and of autophagy in GBM cells, seems to be mediated by increased ceramide production (Dumitru et al., 2018). Another mechanism by which cannabinoids induce GBM cell apoptosis involves increased ROS production and oxidative stress (Massi et al., 2010). Increased ROS-production also showed to mediate cannabinoidsinduced inhibition of glioma stem cells self-renewal (Singer et al., 2015). On the other hand, THC inhibits the cell cycle progression in GBM by decreasing the levels of E2F1 and Cyclin A while increasing the level of the cell cycle inhibitor p16 (Galanti et al., 2008). Furthermore, cannabinoids also showed to inhibit angiogenesis by decreasing VEGF levels (Blázquez et al., 2008). Additionally, cannabinoids have a role in the treatment of cancer as palliative interventions against nausea, vomiting, pain, anxiety, and sleep disturbances; and today's scientific results suggest that cannabinoids could play an important role in palliative care of brain tumor patients (Likar and Nahler, 2017).

\section{Conclusions}

Cannabinoids are effective in reducing tumour growth in animal models of GBM. Besides, treatment efficacy was observed for different types of cannabinoids, alone or in combination, and different treatment durations. The results also showed the presence of publication bias, which, however, do not invalidate the efficacy of cannabinoids. These results in experimental GBM models are promising and highlights the importance of cannabinoid translational research which may lead to clinically relevant studies.

\section{Acknowledgments}

Ângelo Luís acknowledges the contract of Scientific Employment in the scientific area of Microbiology financed by Fundação para a Ciência e a Tecnologia (FCT). This work was funded by a CENTRO 2020 and LISBOA 2020 (POCI-01-0145-FEDER-016822) and FCT (PTDC/BIM-ONC/7121/2014) research Grant and was partially supported by 
CICS-UBI that is financed by National Funds from FCT (UID/Multi/00709/2019). Authors would also like to thank to "Operação Centro-01-0145-FEDER-000019-C4Centro de Competências em Cloud Computing", co-financed by the CENTRO 2020.

Conflicts of interest: None to declare.

\section{References}

Aguado, T., Carracedo, A., Julien, B., Velasco, G., Milman, G., Mechoulamluis, R., Alvarez, L., Guzmán, M., Galve-Roperh, I., 2007. Cannabinoids induce glioma stem-like cell differentiation and inhibit gliomagenesis. J. Biol. Chem. 282, 68546862. doi:10.1074/jbc.M608900200

Allister, S.D., Chan, C., Taft, R.J., Luu, T., Abood, M.E., Moore, D.H., Aldape, K., Yount, G., 2005. Cannabinoids selectively inhibit proliferation and induce death of cultured human glioblastoma multiforme cells. J. Neurooncol. 74, 31-40. doi:10.1007/s11060-004-5950-2

Amarasingh, S., Macleod, M.R., Whittle, I.R., 2009. What is the translational efficacy of chemotherapeutic drug research in neuro-oncology? A systematic review and metaanalysis of the efficacy of BCNU and CCNU in animal models of glioma. J. Neurooncol. 91, 117-125. doi:10.1007/s11060-008-9697-z

Blázquez, C., Carracedo, A., Salazar, M., Lorente, M., Egia, A., González-Feria, L., Haro, A., Velasco, G., Guzmán, M., 2008. Down-regulation of tissue inhibitor of metalloproteinases-1 in gliomas: a new marker of cannabinoid antitumoral activity? Neuropharmacology 54, 235-243. doi:10.1016/j.neuropharm.2007.06.021

Borenstein, M., Hedges, L., Higgins, J., 2009. Introduction to meta-analysis. John Wiley \& Sons, Chichester (UK).

Carracedo, A., Lorente, M., Egia, A., Blázquez, C., García, S., Giroux, V., Malicet, C., Villuendas, R., Gironella, M., González-Feria, L., Piris, M.Á., Iovanna, J.L., Guzmán, M., Velasco, G., 2006. The stress-regulated protein p8 mediates cannabinoid-induced apoptosis of tumor cells. Cancer Cell 9, 301-312. doi:10.1016/j.ccr.2006.03.005

Dall'Stella, P.B., Docema, M.F.L., Maldaun, M.V.C., Feher, O., Lancellotti, C.L.P., 2019. Case report: Clinical outcome and image response of two patients with secondary high-grade glioma treated with chemoradiation, PCV, and cannabidiol. Front. Oncol. 9, 1-7. doi:10.3389/fonc.2018.00643 
Dumitru, C.A., Sandalcioglu, I.E., Karsak, M., 2018. Cannabinoids in Glioblastoma Therapy: New Applications for Old Drugs. Front. Mol. Neurosci. 11, Article 159. doi:10.3389/fnmol.2018.00159

Duntsch, C., Divi, M.K., Jones, T., Zhou, Q., Krishnamurthy, M., Boehm, P., Wood, G., Sills, A., More, B.M., 2006. Safety and efficacy of a novel cannabinoid chemotherapeutic, KM-233, for the treatment of high-grade glioma. J. Neurooncol. 77, 143-152. doi:10.1007/s11060-005-9031-y

Duval, S., Tweedie, R., 2000a. A non parametric "trim and fill" method of accounting for publication bias in meta-analysis. J. Am. Stat. Assoc. 95, 89-98.

Duval, S., Tweedie, R., 2000b. Trim and fill: A simple funnel-plot-based method of testing and adjusting for publication bias in meta-analysis. Biometrics 56, 455-463.

Egger, M., Davey Smith, G., Schneider, M., Minder, C., 1997. Bias in meta-analysis detected by a simple, graphical test. BMJ 315, 629-634.

Erices, J.I., Torres, Á., Niechi, I., Bernales, I., Quezada, C., 2018. Current natural therapies in the treatment against glioblastoma. Phyther. Res. 32, 2191-2201. doi:10.1002/ptr.6170

Fisher, T., Golan, H., Schiby, G., Prichen, S., Smoum, R., Moshe, I., Peshes-Yaloz, N., Castiel, A., Waldman, D., Gallily, R., Mechoulam, R., Toren, A., 2016. In vitro and in vivo efficacy of non-psychoactive cannabidiol in neuroblastoma. Curr. Oncol. 23, S15-S22. doi:10.3747/co.23.2893

Galanti, G., Fisher, T., Kventsel, I., Shoham, J., Gallily, R., Mechoulam, R., Lavie, G., Amariglio, N., Rechavi, G., Toren, A., 2008. $\Delta^{9}$-Tetrahydrocannabinol inhibits cell cycle progression by downregulation of E2F1 in human glioblastoma multiforme cells. Acta Oncol. 47, 1062-1070. doi:10.1080/02841860701678787

Gurley, S.N., Abidi, A.H., Allison, P., Guan, P., Duntsch, C., Robertson, J.H., Kosanke, S.D., Keir, S.T., Bigner, D.D., Elberger, A.J., Moore, B.M., 2012. Mechanism of anti-glioma activity and in vivo efficacy of the cannabinoid ligand KM-233. J. Neurooncol. 110, 163-177. doi:10.1007/s11060-012-0958-5

Guzmán, M., Duarte, M.J., Blázquez, C., Ravina, J., Rosa, M.C., Galve-Roperh, I., Sánchez, C., Velasco, G., González-Feria, L., 2006. A pilot clinical study of $\Delta^{9}-$ tetrahydrocannabinol in patients with recurrent glioblastoma multiforme. Br. J. Cancer 95, 197-203. doi:10.1038/sj.bjc.6603236

Hernán Pérez de la Ossa, D., Lorente, M., Gil-Alegre, M.E., Torres, S., García-Taboada, E., Aberturas, M. del R., Molpeceres, J., Velasco, G., Torres-Suárez, A.I., 2013. 
Local Delivery of Cannabinoid-Loaded Microparticles Inhibits Tumor Growth in a Murine Xenograft Model of Glioblastoma Multiforme. PLoS One 8, e54795. doi:10.1371/journal.pone.0054795

Higgins, J., Thompson, S.G., Deeks, J.J., Altman, D.G., 2003. Measuring inconsistency in meta-analyses. BMJ 327, 557-560.

Hirst, J.A., Howick, J., Aronson, J.K., Roberts, N., Perera, R., Koshiaris, C., Heneghan, C., 2014. The need for randomization in animal trials: An overview of systematic reviews. PLoS One 9, e98856. doi:10.1371/journal.pone.0098856

Hirst, T.C., Vesterinen, H.M., Conlin, S., Egan, K.J., Antonic, A., Lawson McLean, A., Macleod, M.R., Grant, R., Brennan, P.M., Sena, E.S., Whittle, I.R., 2014. A systematic review and meta-analysis of gene therapy in animal models of cerebral glioma: why did promise not translate to human therapy? Evidence-based Preclin. Med. 1, 21-33. doi:10.1002/ebm2.6

Hooijmans, C.R., IntHout, J., Ritskes-Hoitinga, M., Rovers, M.M., 2014. Meta-analyses of animal studies: An introduction of a valuable instrument to further improve healthcare. ILAR J. 55, 418-426. doi:10.1093/ilar/ilu042

Kenyon, J., Liu, W., Dalgleish, A., 2018. Report of objective clinical responses of cancer patients to pharmaceutical-grade synthetic cannabidiol. Anticancer Res. 38, 58315835. doi:10.21873/anticanres.12924

Ladin, D.A., Soliman, E., Griffin, L.T., Van Dross, R., 2016. Preclinical and clinical assessment of cannabinoids as anti-cancer agents. Front. Pharmacol. 7, Article 361. doi:10.3389/fphar.2016.00361

Light, R.J., Pillemer, D.B., 1984. Summing up: The Science of Reviewing Research. Harvard University Press, Cambridge, MA.

Light, R.J., Singer, J.D., Willett, J.B., 1994. The visual presentation and interpretation of meta-analyses, in: Cooper, M., Hedges, L. V. (Eds.), The Handbook of Research Synthesis. Russell Sage Foundation, New York.

Likar, R., Nahler, G., 2017. The use of cannabis in supportive care and treatment of brain tumor. Neuro-Oncology Pract. 4, 151-160. doi:10.1093/nop/npw027

López-Valero, I., Saiz-Ladera, C., Torres, S., Hernández-Tiedra, S., García-Taboada, E., Rodríguez-Fornés, F., Barba, M., Dávila, D., Salvador-Tormo, N., Guzmán, M., Sepúlveda, J.M., Sánchez-Gómez, P., Lorente, M., Velasco, G., 2018a. Targeting Glioma Initiating Cells with A combined therapy of cannabinoids and temozolomide. Biochem. Pharmacol. 157, 266-274. doi:10.1016/j.bcp.2018.09.007 
López-Valero, I., Torres, S., Salazar-Roa, M., García-Taboada, E., Hernández-Tiedra, S., Guzmán, M., Sepúlveda, J.M., Velasco, G., Lorente, M., 2018b. Optimization of a preclinical therapy of cannabinoids in combination with temozolomide against glioma. Biochem. Pharmacol. 157, 275-284. doi:10.1016/j.bcp.2018.08.023

Lorente, M., Torres, S., Salazar, M., Carracedo, A., Hernández-Tiedra, S., RodríguezFornés, F., García-Taboada, E., Meléndez, B., Mollejo, M., Campos-Martín, Y., Lakatosh, S.A., Barcia, J., Guzmán, M., Velasco, G., 2011. Stimulation of the midkine/ALK axis renders glioma cells resistant to cannabinoid antitumoral action. Cell Death Differ. 18, 959-973. doi:10.1038/cdd.2010.170

Massi, P., Vaccani, A., Ceruti, S., Colombo, A., Abbracchio, M.P., Parolaro, D., 2004. Antitumor Effects of Cannabidiol, a Nonpsychoactive Cannabinoid, on Human Glioma Cell Lines. J. Pharmacol. Exp. Ther. 308, 838-845. doi:10.1124/jpet.103.061002

Massi, P., Valenti, M., Solinas, M., Parolaro, D., 2010. Molecular mechanisms involved in the antitumor activity of cannabinoids on gliomas: Role for oxidative stress. Cancers. 2, 1013-1026. doi:10.3390/cancers2021013

McAllister, S.D., Soroceanu, L., Desprez, P.Y., 2015. The Antitumor Activity of PlantDerived Non-Psychoactive Cannabinoids. J. Neuroimmune Pharmacol. 10, 255267. doi:10.1007/s11481-015-9608-y

Moher, D., Liberati, A., Tetzlaff, J., Altman, D.G., Grp, P., 2009. Preferred Reporting Items for Systematic Reviews and Meta-Analyses: The PRISMA Statement. Ann. Intern. Med. 151, 264-270. doi:10.1371/journal.pmed.1000097

Moher, D., Shamseer, L., Clarke, M., Ghersi, D., Liberati, A., Petticrew, M., Shekelle, P., Stewart, L.A., Group, P.-P., 2015. Preferred Reporting Items for Systematic Review and Meta-Analysis Protocols (PRISMA-P) 2015 statement. Syst. Rev. 4, 1-9. doi:10.1186/2046-4053-4-1

Recht, L.D., Salmonsen, R., Rosetti, R., Jang, T., Pipia, G., Kubiatowski, T., Karim, P., Ross, A.H., Zurier, R., Scott Litofsky, N., Burstein, S., 2001. Antitumor effects of ajulemic acid (CT3), a synthetic non-psychoactive cannabinoid. Biochem. Pharmacol. 62, 755-763. doi:10.1016/S0006-2952(01)00700-6

Rocha, F.C.M., Dos Santos Júnior, J.G., Stefano, S.C., Da Silveira, D.X., 2014. Systematic review of the literature on clinical and experimental trials on the antitumor effects of cannabinoids in gliomas. J. Neurooncol. 116, 11-24. doi:10.1007/s11060-013-1277-1 
Sánchez, C., de Ceballos, M.L., Gomez del Pulgar, T., Rueda, D., Corbacho, C., Velasco, G., Galve-Roperh, I., Huffman, J.W., Ramón y Cajal, S., Guzmán, M., 2001a. Inhibition of glioma growth in vivo by selective activation of the $\mathrm{CB}(2)$ cannabinoid receptor. Cancer Res. 61, 5784-5789.

Sánchez, C., de Ceballos, M.L., Gomez del Pulgar, T., Rueda, D., Corbacho, C., Velasco, G., Galve-Roperh, I., Huffman, J.W., Ramón y Cajal, S., Guzmán, M., 2001b. Inhibition of glioma growth in vivo by selective activation of the $\mathrm{CB}(2)$ cannabinoid receptor. Cancer Res. 61, 5784-5789.

Schultz, S., Beyer, M., 2017. GW Pharmaceuticals Achieves Positive Results in Phase 2 Proof of Concept Study in Glioma, https://www.globenewswire.com/newsrelease/2017/02/07/914583/0/en/GW-Pharmaceuticals-Achieves-Positive-Resultsin-Phase-2-Proof-of-Concept-Study-in-Glioma.html (assessed 30 November 2019).

Sena, E.S., Currie, G.L., McCann, S.K., Macleod, M.R., Howells, D.W., 2014. Systematic reviews and meta-analysis of preclinical studies: Why perform them and how to appraise them critically. J. Cereb. Blood Flow Metab. 34, 737-742. doi:10.1038/jcbfm.2014.28

Silva, A.G., Lopes, C.F.B., Carvalho Júnior, C.G., Thomé, R.G., dos Santos, H.B., Reis, R., Ribeiro, R.I.M. de A., 2019. WIN55,212-2 induces caspase-independent apoptosis on human glioblastoma cells by regulating HSP70, p53 and Cathepsin D. Toxicol. Vitr. 57, 233-243. doi:10.1016/j.tiv.2019.02.009

Singer, E., Judkins, J., Salomonis, N., Matlaf, L., Soteropoulos, P., McAllister, S., Soroceanu, L., 2015. Reactive oxygen species-mediated therapeutic response and resistance in glioblastoma. Cell Death Dis. 6, e1601. doi:10.1038/cddis.2014.566

Soroceanu, L., Murase, R., Limbad, C., Singer, E., Allison, J., Adrados, I., Kawamura, R., Pakdel, A., Fukuyo, Y., Nguyen, D., Khan, S., Arauz, R., Yount, G.L., Moore, D.H., Desprez, P.Y., McAllister, S.D., 2013. Id-1 is a key transcriptional regulator of glioblastoma aggressiveness and a novel therapeutic target. Cancer Res. 73, 15591569. doi:10.1158/0008-5472.CAN-12-1943

Stupp, R., Mason, W.P., van den Bent, M.J., Weller, M., Fisher, B., Taphoorn, M.J.B., Belanger, K., Brandes, A.A., Marosi, C., Bogdahn, U., Curschmann, J., Janzer, R.C., Ludwin, S.K., Gorlia, T., Allgeier, A., Lacombe, D., Cairncross, J.G., Eisenhauer, E., Mirimanoff, R.O., 2005. Radiotherapy plus Concomitant and Adjuvant Temozolomide for Glioblastoma. N. Engl. J. Med. 352, 987-996. doi:10.1056/NEJMoa043330 
Torres, S., Lorente, M., Rodriguez-Fornes, F., Hernandez-Tiedra, S., Salazar, M., GarciaTaboada, E., Barcia, J., Guzman, M., Velasco, G., 2011. A Combined Preclinical Therapy of Cannabinoids and Temozolomide against Glioma. Mol. Cancer Ther. 10, 90-103. doi:10.1158/1535-7163.mct-10-0688

Velasco, G., Carracedo, A., Blázquez, C., Lorente, M., Aguado, T., Haro, A., Sánchez, C., Galve-Roperh, I., Guzmán, M., 2007. Cannabinoids and gliomas. Mol. Neurobiol. 36, 60-67. doi:10.1007/s12035-007-0002-5

Vesterinen, H.M., Sena, E.S., Egan, K.J., Hirst, T.C., Churolov, L., Currie, G.L., Antonic, A., Howells, D.W., Macleod, M.R., 2014. Meta-analysis of data from animal studies: A practical guide. J. Neurosci. Methods 221, 92-102. doi:10.1016/j.jneumeth.2013.09.010 
Table 1: Characteristics of the 22 included studies in this systematic review with meta-analysis.

\begin{tabular}{|c|c|c|c|c|c|c|c|}
\hline Study* & Year & Cells & Intervention & Outcome analysed & Model used & Dose (per day) & $\begin{array}{c}\text { Duration of } \\
\text { the treatment }\end{array}$ \\
\hline López-Valero, et al A) 1) & 2018 & \multirow{3}{*}{ Human GBM line (U87MG) } & \multirow{3}{*}{$\begin{array}{l}\text { Evaluation of the effect of cannabidiol (CBD) } \\
\text { and tetrahydrocannabinol (THC) alone or in } \\
\text { combination (CBD+THC), and in combination } \\
\text { with temozolomide (TMZ) in apoptosis, } \\
\text { migration, animal survival and tumour volume in } \\
\text { tumour xenografts (mice inoculated with } \\
\text { U87MG cells) }\end{array}$} & \multirow{3}{*}{ Tumour volume } & $\begin{array}{c}\text { Subcutaneous } \\
\text { xenografts }\end{array}$ & CBD (15 mg/kg) & 15 days \\
\hline López-Valero, et al A) 2) & 2018 & & & & $\begin{array}{c}\text { Subcutaneous } \\
\text { xenografts }\end{array}$ & $\begin{array}{l}\text { THC:CBD }(1: 4) \\
(\text { THC } 6.5 \mathrm{mg} / \mathrm{kg}+ \\
\text { CBD } 24.5 \mathrm{mg} / \mathrm{kg})\end{array}$ & 14 days \\
\hline López-Valero, et al A) 3) & 2018 & & & & $\begin{array}{l}\text { Intracranial } \\
\text { xenografts }\end{array}$ & $\begin{array}{l}\text { THC:CBD }(1: 4) \\
(\text { THC } 6.5 \mathrm{mg} / \mathrm{kg}+ \\
\text { CBD } 24.5 \mathrm{mg} / \mathrm{kg}) \\
\end{array}$ & 14 days \\
\hline López-Valero, et al B) 1) & 2018 & \multirow{5}{*}{ Human GBM line (U87MG) } & \multirow{5}{*}{$\begin{array}{l}\text { Evaluation of the effect of CBD+THC }(1: 1) \text { in } \\
\text { combination of TMZ on tumour volume and } \\
\text { animal survival in tumour xenogrfts } \\
\text { (mice inoculated with U87MG cells) }\end{array}$} & \multirow{5}{*}{ Tumour volume } & $\begin{array}{c}\text { Subcutaneous } \\
\text { xenografts }\end{array}$ & THC (15 mg/kg) & 15 days \\
\hline López-Valero, et al B) 2) & 2018 & & & & $\begin{array}{c}\text { Subcutaneous } \\
\text { xenografts }\end{array}$ & $\begin{array}{l}\text { THC:CBD }(1: 1) \\
(\mathrm{THC} 15 \mathrm{mg} / \mathrm{kg}+ \\
\text { CBD } 15 \mathrm{mg} / \mathrm{kg}) \\
\text { peritumoural } \\
\text { administration }\end{array}$ & 12 days \\
\hline López-Valero, et al B) 3) & 2018 & & & & $\begin{array}{c}\text { Subcutaneous } \\
\text { xenografts }\end{array}$ & $\begin{array}{l}\text { THC:CBD }(1: 1) \\
\text { (THC } 15 \mathrm{mg} / \mathrm{kg}+ \\
\text { CBD } 15 \mathrm{mg} / \mathrm{kg}) \\
\text { oral administration }\end{array}$ & 12 days \\
\hline López-Valero, et al B) 4) & 2018 & & & & $\begin{array}{c}\text { Subcutaneous } \\
\text { xenografts }\end{array}$ & $\begin{array}{l}\text { THC:CBD }(1: 1) \\
\text { (THC } 45 \mathrm{mg} / \mathrm{kg}+ \\
\text { CBD } 45 \mathrm{mg} / \mathrm{kg}) \\
\text { oral administration }\end{array}$ & 12 days \\
\hline López-Valero, et al B) 5) & 2018 & & & & $\begin{array}{l}\text { Intracranial } \\
\text { xenografts }\end{array}$ & $\begin{array}{l}\text { THC:CBD }(1: 1) \\
(\text { THC } 7.5 \mathrm{mg} / \mathrm{kg}+ \\
\text { CBD } 7.5 \mathrm{mg} / \mathrm{kg})\end{array}$ & 7 days \\
\hline Ossa, et al 1) & 2013 & \multirow{3}{*}{ Human GBM line (U87MG) } & \multirow{3}{*}{$\begin{array}{l}\text { Evaluation of the effect of CBD, THC or } \\
\text { CBD+THC (1:1), in solution or microparticles on } \\
\text { apoptosis, migration, angiogenesis and on } \\
\text { tumour volume of tumour xenografts } \\
\text { (mice inoculated with U87MG cells) }\end{array}$} & \multirow{3}{*}{ Tumour volume } & $\begin{array}{c}\text { Subcutaneous } \\
\text { xenografts }\end{array}$ & THC (15 mg/kg) & 22 days \\
\hline Ossa, et al 2) & 2013 & & & & $\begin{array}{c}\text { Subcutaneous } \\
\text { xenografts } \\
\end{array}$ & CBD $(15 \mathrm{mg} / \mathrm{kg})$ & 22 days \\
\hline Ossa, et al 3) & 2013 & & & & $\begin{array}{c}\text { Subcutaneous } \\
\text { xenografts }\end{array}$ & $\begin{array}{c}\text { THC:CBD }(1: 1) \\
(\text { THC } 7.5 \mathrm{mg} / \mathrm{kg}+ \\
\text { CBD } 7.5 \mathrm{mg} / \mathrm{kg}) \\
\end{array}$ & 22 days \\
\hline Gurley, et al 1) & 2012 & \multirow{2}{*}{ Human GBM line (U87MG) } & \multirow{2}{*}{$\begin{array}{c}\text { Evaluation of the effect of the cannabinoid KM- } \\
233 \text { on tumour volume of tumour xenografts } \\
\text { (mice inoculated with U87MG cells) }\end{array}$} & \begin{tabular}{|c|} 
Tumour volume (model \\
D-08-0673 MG) \\
\end{tabular} & $\begin{array}{c}\text { Subcutaneous } \\
\text { xenografts } \\
\end{array}$ & $\begin{array}{c}\mathrm{KM}-233 \\
(24 \mathrm{mg} / \mathrm{kg})\end{array}$ & 35 days \\
\hline Gurley, et al 2) & 2012 & & & $\begin{array}{c}\text { Tumour volume (model } \\
\text { D-09-0363 MG) }\end{array}$ & $\begin{array}{c}\text { Subcutaneous } \\
\text { xenografts }\end{array}$ & $\begin{array}{c}\mathrm{KM}-233 \\
(24 \mathrm{mg} / \mathrm{kg})\end{array}$ & 15 days \\
\hline
\end{tabular}




\begin{tabular}{|c|c|c|c|c|c|c|c|}
\hline Torres, et al 1) & 2011 & \multirow{4}{*}{$\begin{array}{l}\text { Human GBM lines (U87MG } \\
\text { and T98G) }\end{array}$} & \multirow{4}{*}{$\begin{array}{c}\text { Evaluation of the effect of CBD, THC, alone or } \\
\text { in combination with TMZ on } \\
\text { viability/proliferation, apoptosis and tumour } \\
\text { volume of tumour xenografts } \\
\text { (mice inoculated with U87MG cells) }\end{array}$} & \multirow{4}{*}{ Tumour volume } & $\begin{array}{c}\text { Subcutaneous } \\
\text { xenografts }\end{array}$ & THC (15 mg/kg) & 15 days \\
\hline Torres, et al 2) & 2011 & & & & \begin{tabular}{|c|}
$\begin{array}{c}\text { Subcutaneous } \\
\text { xenografts }\end{array}$ \\
\end{tabular} & CBD $(7.5 \mathrm{mg} / \mathrm{kg})$ & 15 days \\
\hline Torres, et al 3) & 2011 & & & & \begin{tabular}{|c|}
$\begin{array}{c}\text { Subcutaneous } \\
\text { xenografts }\end{array}$ \\
\end{tabular} & THC (7.5 mg/kg) & 15 days \\
\hline Torres, et al 4) & 2011 & & & & $\begin{array}{c}\text { Subcutaneous } \\
\text { xenografts }\end{array}$ & $\begin{array}{l}\text { THC:CBD }(1: 1) \\
\text { (THC } 7.5 \mathrm{mg} / \mathrm{kg}+ \\
\text { CBD } 7.5 \mathrm{mg} / \mathrm{kg})\end{array}$ & 15 days \\
\hline Lorente, et al 1) & 2011 & \multirow{2}{*}{$\begin{array}{l}\text { Human GBM lines (GOS3, } \\
\text { U87MG, A172, SW1783, } \\
\text { U118MG, U373MG, T98G and } \\
\text { SW1088) }\end{array}$} & \multirow{2}{*}{$\begin{array}{l}\text { Evaluation of the effect of THC on viability, } \\
\text { apoptosis and tumour volume on tumour } \\
\text { xenografts. Influence of expression levels of } \\
\text { midkine/ALK on THC efficacy }\end{array}$} & \multirow{2}{*}{ Tumour volume } & \begin{tabular}{|c|} 
Subcutaneous \\
xenografts \\
(derived from \\
T98 cells) \\
\end{tabular} & THC (15 mg/kg) & 15 days \\
\hline Lorente, et al 2) & 2011 & & & & \begin{tabular}{|c|}
$\begin{array}{c}\text { Subcutaneous } \\
\text { xenografts } \\
\text { (derived from } \\
\text { T98 cells) }\end{array}$ \\
\end{tabular} & THC (15 mg/kg) & 15 days \\
\hline Massi, et al & 2004 & $\begin{array}{l}\text { Human GBM lines (U86MG } \\
\text { and U373) }\end{array}$ & $\begin{array}{c}\text { Evaluation of the effect of CBD on proliferation, } \\
\text { apoptosis and tumour volume on tumour } \\
\text { xenografts } \\
\text { (mice inoculated with U87MG cells) }\end{array}$ & Tumour volume & $\begin{array}{c}\text { Subcutaneous } \\
\text { xenografts }\end{array}$ & $\begin{array}{c}\text { CBD } \\
(0.5 \mathrm{mg} / \text { mouse })\end{array}$ & 23 days \\
\hline Sánchez, et al & 2001 & $\begin{array}{l}\text { Human tumour cells prepared } \\
\text { from a grade IV astrocytoma }\end{array}$ & $\begin{array}{c}\text { Evaluation of the effect of JWH-133 on tumour } \\
\text { size of tumour xenografts } \\
\text { (mice immunotolerant - Rag-2 }- \text { ) }\end{array}$ & Tumour size & $\begin{array}{c}\text { Subcutaneous } \\
\text { xenografts }\end{array}$ & $\begin{array}{c}\text { JWH-133 } \\
(50 \mu \mathrm{g} \text { injected } \\
\text { intratumourally/day })\end{array}$ & 25 days \\
\hline Carracedo, et al & 2006 & $\begin{array}{l}\text { Human GBM line (U87MG) } \\
\text { and mice embrionary fibroblasts } \\
\text { (MEF) }\end{array}$ & $\begin{array}{c}\text { Evaluation of the effect of THC on viability, } \\
\text { apoptosis and tumour volume on tumour } \\
\text { xenografts } \\
\text { (mice inoculated with U87MG cells and MEF) }\end{array}$ & Tumour volume & \begin{tabular}{|c|}
$\begin{array}{c}\text { Subcutaneous } \\
\text { xenografts } \\
\text { (derived from } \\
\text { U87MG } \\
\text { cells) }\end{array}$ \\
\end{tabular} & THC (15 mg/kg) & 14 days \\
\hline
\end{tabular}

*The numbers in unpaired parenthesis indicate the division of each work in several studies. 
Table 2: Effects of cannabinoids on GBM growth.

\begin{tabular}{|c|c|c|c|c|c|c|c|}
\hline $\begin{array}{c}\text { Outcome } \\
\text { analysed }\end{array}$ & $\begin{array}{c}\text { Number } \\
\text { of studies }\end{array}$ & $\begin{array}{c}\text { Number of } \\
\text { animals }\end{array}$ & $\begin{array}{c}\text { WSDM observed } \\
(\mathbf{9 5 \%} \mathbf{C I})\end{array}$ & $\boldsymbol{p}$-value & $\left.\mathbf{I}^{\mathbf{2}} \mathbf{\%}\right)$ & $\begin{array}{c}\text { Model } \\
\text { used }\end{array}$ & $\begin{array}{c}\text { WSDM adjusted } \\
\text { for absence of } \\
\text { bias } \\
\text { (95\% CI) }\end{array}$ \\
\hline $\begin{array}{c}\text { Tumour volume } \\
\text { (fold of increase) }\end{array}$ & 22 & 301 & $\begin{array}{c}-1.399 \\
(-1.900 \text { to }-0.898)\end{array}$ & $<0.0001^{*}$ & 72 & Random & $\begin{array}{c}-1.606 \\
(-2.135 \text { to }-1.077)\end{array}$ \\
\hline
\end{tabular}

WSDM - weighted standardized difference in means; CI - confidence interval; *Indicates a significant result. 
Table 3: Subgroup analysis of the effects of cannabinoids on GBM growth.

\begin{tabular}{|c|c|c|c|c|}
\hline \multirow{2}{*}{ Variable } & \multicolumn{4}{|c|}{ GBM growth } \\
\hline & Number of studies & $95 \% \mathrm{CI}$ & $p$-value & $\mathbf{I}^{2}(\%)$ \\
\hline Total & 22 & - & - & - \\
\hline WSDM observed & - & $\begin{array}{c}-1.399 \\
(-1.900 \text { to }-0.898)\end{array}$ & $<0.0001^{*}$ & 72 \\
\hline $\begin{array}{l}\text { WSDM adjusted for } \\
\text { absence of bias }\end{array}$ & - & $\begin{array}{c}-1.606 \\
(-2.135 \text { to }-1.077)\end{array}$ & - & - \\
\hline \multicolumn{5}{|c|}{ Model used } \\
\hline subcutaneous xenografts & 20 & $\begin{array}{c}-1.512 \\
(-2.060 \text { to }-0.965)\end{array}$ & $<0.0001 *$ & 74 \\
\hline intracranial xenografts & 2 & $\begin{array}{c}-0.738 \\
(-2.091 \text { to } 0.616)\end{array}$ & 0.286 & 55 \\
\hline \multicolumn{5}{|c|}{ Cannabinoids } \\
\hline CBD & 4 & $\begin{array}{c}-1.075 \\
(-2.082 \text { to }-0.069)\end{array}$ & $0.036^{*}$ & 15 \\
\hline JWH-133 & 1 & $\begin{array}{c}-6.641 \\
(-9.972 \text { to }-3.310)\end{array}$ & $<0.0001 *$ & 0 \\
\hline KM-233 & 2 & $\begin{array}{c}-0.103 \\
(-1.456 \text { to } 1.251)\end{array}$ & 0.882 & 0 \\
\hline THC & 7 & $\begin{array}{c}-1.757 \\
(-2.571 \text { to }-0.944)\end{array}$ & $<0.0001^{*}$ & 77 \\
\hline THC+CBD & 8 & $\begin{array}{c}-1.301 \\
(-2.039 \text { to }-0.564)\end{array}$ & $0.001 *$ & 62 \\
\hline \multicolumn{5}{|c|}{ Duration of the treatment (days) } \\
\hline 8 & 1 & $\begin{array}{c}-1.489 \\
(-3.995 \text { to } 1.017)\end{array}$ & 0.244 & 0 \\
\hline 12-15 & 15 & $\begin{array}{c}-1.495 \\
(-2.128 \text { to }-0.862)\end{array}$ & $<0.0001^{*}$ & 73 \\
\hline 22-27 & 5 & $\begin{array}{c}-1.480 \\
(-2.598 \text { to }-0.362)\end{array}$ & $0.009 *$ & 76 \\
\hline 35 & 1 & $\begin{array}{c}-0.008 \\
(-2.294 \text { to } 2.277)\end{array}$ & 0.994 & 0 \\
\hline
\end{tabular}

WSDM - weighted standardized difference in means; CI - confidence interval; *Indicates a significant result. 
Table 4: Assessment of publication bias for the impact of cannabinoids administration on GBM growth.

\begin{tabular}{|c|c|c|c|c|}
\hline \multirow{2}{*}{ Outcome analysed } & \multicolumn{4}{|c|}{ Egger's regression test } \\
\cline { 2 - 5 } & $\mathbf{9 5 \%}$ CI & $t$ & df & $p$-value \\
\hline Tumour volume & -9.783 to -5.451 & 7.337 & 20 & $<0.00001 *$ \\
(fold of increase) & & & & \\
\hline
\end{tabular}


Figure 1: Flow-diagram of database search, study selection and articles included in this systematic review with meta-analysis.
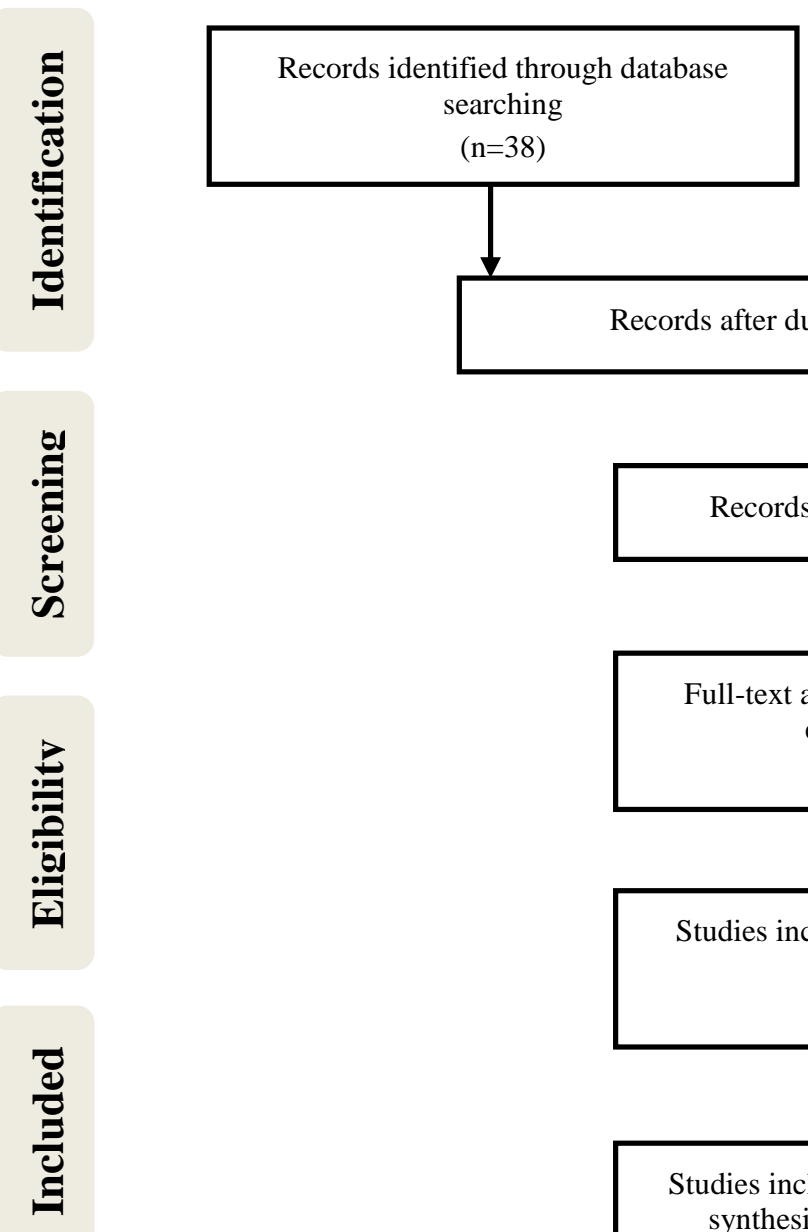
searching
$(\mathrm{n}=38)$

Additional records identified through other sources

$(n=2)$

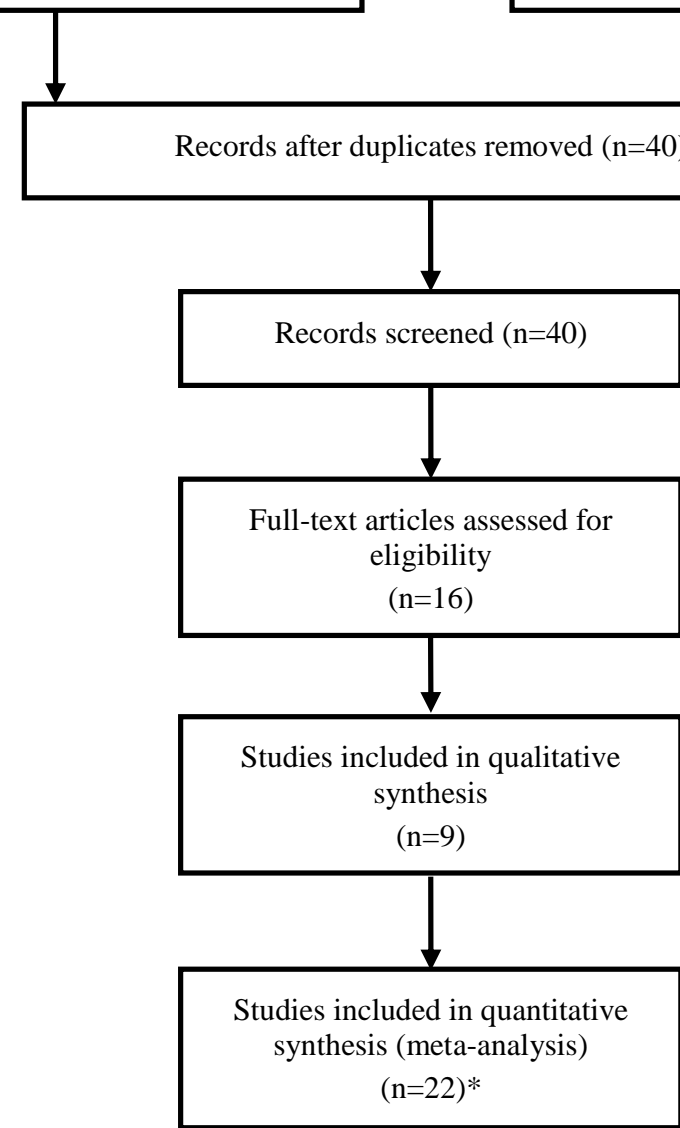

*The work of López-Valero, et al 2018 B) was divided into 5 different studies. The work of Torres, et al 2011 was divided into 4 different studies. The works of López-Valero, et al 2018 A) and Ossa, et al 2013 were divided into 3 different studies. The works of Gurley, et al 2012 and Lorente, et al 2011 were divided into 2 different studies. (The division of each work in several studies is indicated by the numbers in unpaired parenthesis in Table 1) 
Figure 2: Forest plot of comparisons of the effects of cannabinoids on GBM growth.

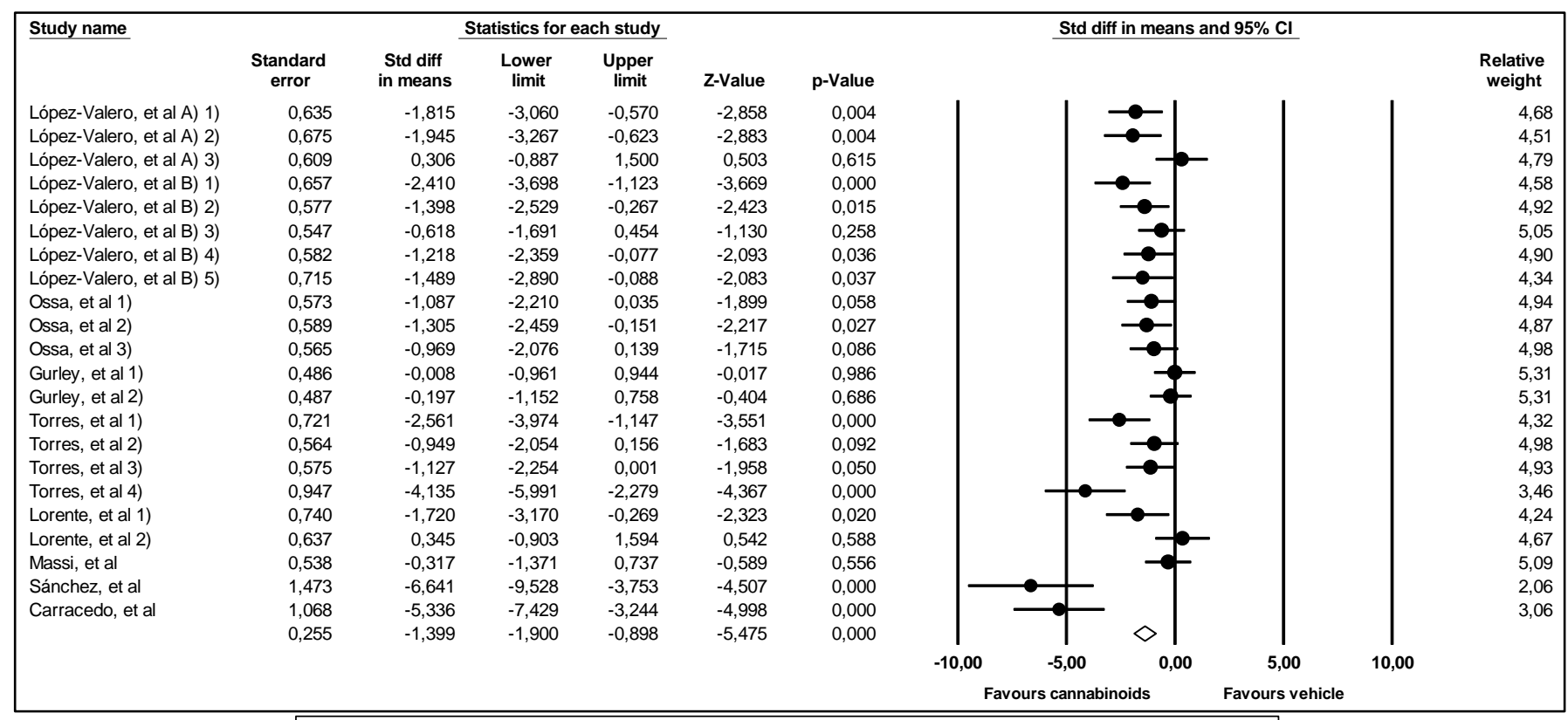

Heterogeneity: $\mathrm{Tau}^{2}=0.993 ; \mathrm{Chi}^{2}=74.427 ; \mathrm{df}=21 ; p$-value $<0.0001 ; \mathrm{I}^{2}=72 \%$

Test for overall effect: $Z=-5.975 ; p$-value $<0.0001$ 
Figure 3: Results of sensitivity analysis.

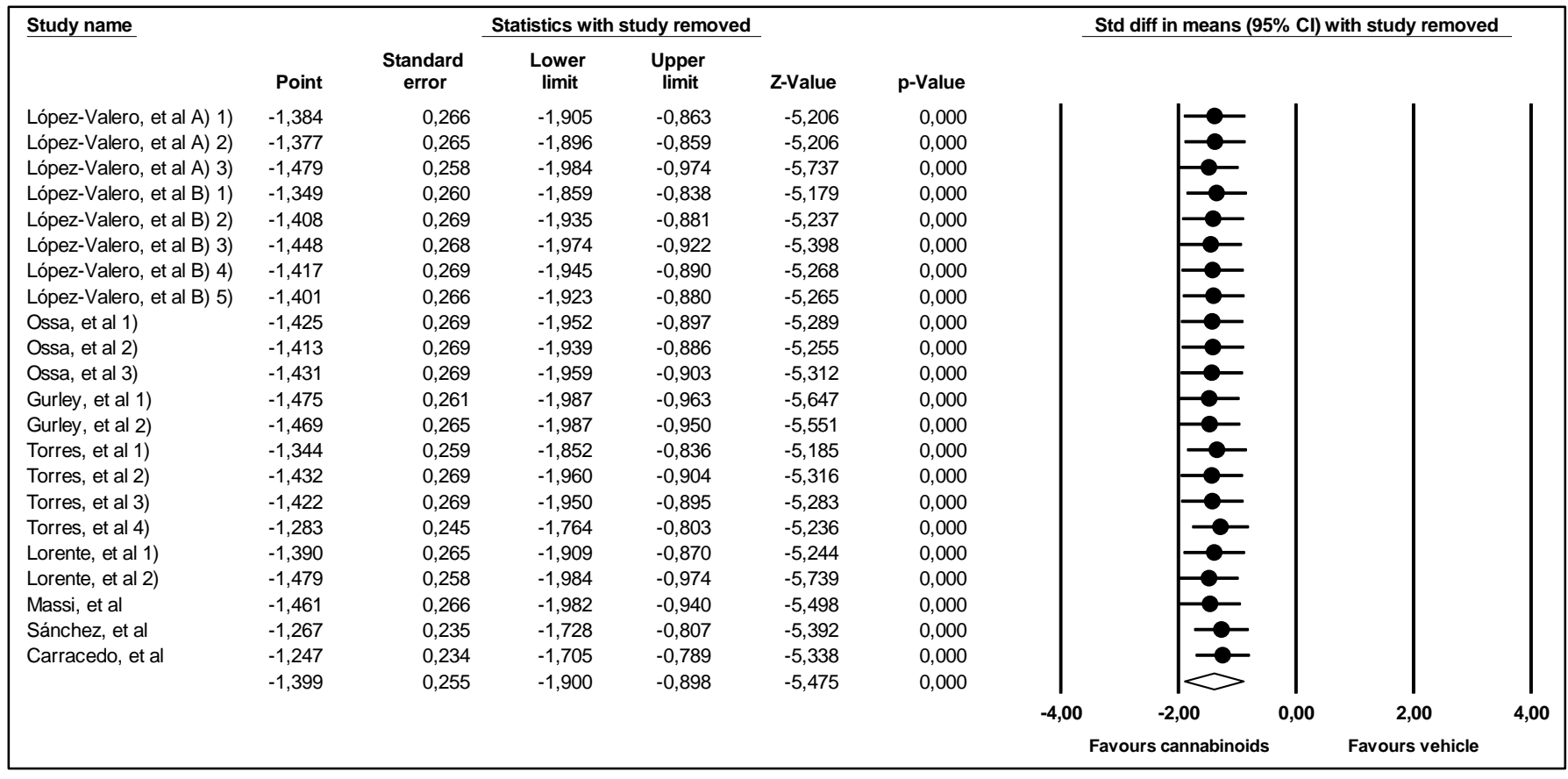


Figure 4: Funnel plot of standard error by difference in means (publication bias tests) of the effects of cannabinoids on GBM growth.

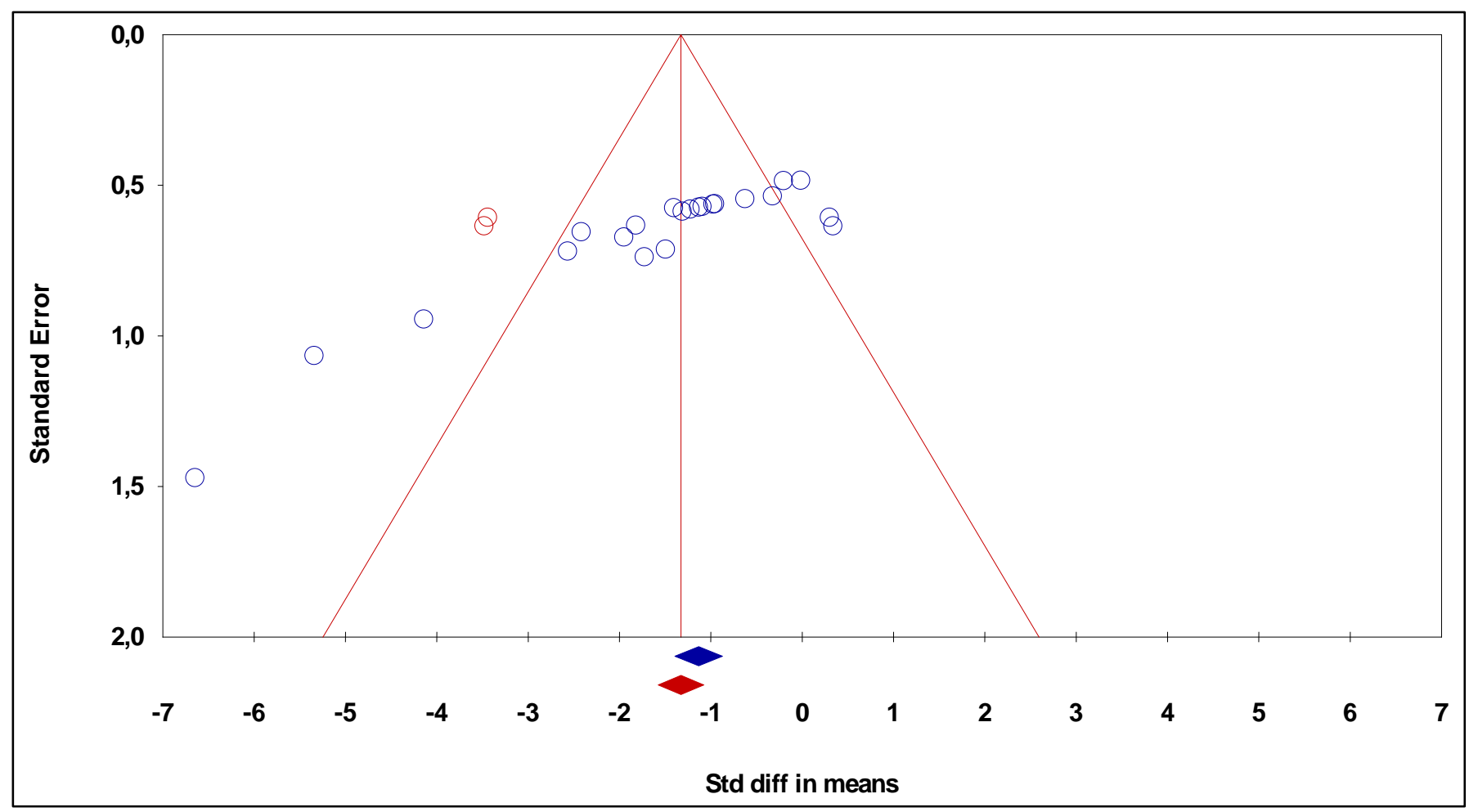

The blue circles indicate the observed studies and the red circles indicate the necessary imputed studies to obtain absence of bias. 